Aim of the study: The objective of the study was to analyse the survival rate of women with malignant ovarian tumours in the years 1990-2015 in the Podkarpacie province.

Material and methods: The database used for calculations covered 2399 cancer incidences verified at the end of 2014. The estimated relative survival rates were calculated by means of the Hakulinen method.

Results: The number of recorded cases amounted to 196 in 2015 and was higher by $86.7 \%$ than in 1990 . The rates of one-year, three-year, and fiveyear survival was $72.5 \%, 51.2 \%$, and $42.4 \%$, respectively.

Conclusions: Survival rates of women with ovarian cancer in the Podkarpacie province are comparable to survivals calculated for the entire Poland region. Despite the low risk factor, women suffering from ovarian adenocarcinoma have lower survival rates than others, and as many as $42.5 \%$ of patients with adenocarcinoma were diagnosed in stage IV. Steps aimed at improvement of detectability of ovarian cancers in the earliest possible stage should be taken. This should increase survival rates in each age group.

Key words: survival rates, ovarian cancer, incidence.

Contemp Oncol (Pozn) 2018; 22 (3): 151-157 DOI: https://doi.org/10.5114/wo.2018.78935

\section{Survival rates among women with ovarian cancers diagnosed in the area of Podkarpacie province in the years 1990-2015}

\author{
Aneta U. Radziszewska ${ }^{1}$, Bożenna Karczmarek-Borowska², \\ Sebastian Wójcik ${ }^{3}$, Tomasz Kluz ${ }^{4}$
}

${ }^{1}$ Department of Epidemiology and Podkarpackie Cancer Registry, Podkarpackie Oncology Centre, Rzeszow, Poland

2Department of Oncology, Faculty of Medical Sciences, University of Rzeszow, Rzeszow, Poland

${ }^{3}$ Department of Mathematical Statistics, Statistical Office in Rzeszow, Rzeszow, Poland ${ }^{4}$ Department of Obstetrics and Gynaecology, Fryderyk Chopin University Hospital No. 1, Faculty of Medicine, University of Rzeszow, Rzeszow, Poland

\section{Introduction}

Despite intensified efforts of the entire medical community, ovarian cancer (C56) remains a neoplasm with the worst prognosis among tumours of reproductive organs and constitutes the most frequent cause of death in women [1]. A total of 3735 new patients with ovarian cancer and 2768 deaths due to ovarian cancer were recorded in Poland in 2015 [2].

According to the expected incidence forecasted by the National Cancer Registry (NCR), the ovarian cancer prevalence will insignificantly decrease until the year 2025 with a simultaneous increase of new episode cases. The increase of ovarian cancer incidence will be visible only in women after the age of 65 years [3]. The lack of a sufficiently accurate screening test and the non-specific character of symptoms in an early stage impede the diagnosis and thus decrease the chance for survival [4]. Screening tests do not even include women with diagnosed mutation in BRCA1 and BRCA2 genes [5, 6]. Only $20-30 \%$ of cases are diagnosed in stage I and II, and the remaining $70 \%$ cases are diagnosed in stage III and IV [7]. One-year survival rates in Poland amount to almost $70 \%$, while $43-50 \%$ of patients survive for five years from the time when the neoplasm is diagnosed [8].

The objective of the thesis was to analyse survival rates among women with ovarian cancers living in the area of Podkarpacie province in the years 1990-2015.

\section{Material and methods}

The database used for calculations covered 2399 cancer cases verified at the end of 2014. It includes date of cancer diagnosis, year of birth (19312014), year of death (in the case of 1261 observations, 1989-2014), patients' age (0-100), stage of tumour, histological type of tumour (67 types), and body area code. For further analysis we have used 1138 observations for which, as of the end of 2014, the treatment was continued or aborted.

Survival function was assessed with a Kaplan-Meier estimator. The data of included patients were used to calculate survival curves.

The estimated relative performance indices were calculated using the Hakulinen method [9] and the regression Cox Model was used for statistical analysis.

\section{Results}

In the analysed period, an increase of crude and standardised rates of incidence of ovarian cancer was recorded: from $13.7 / 10^{5}$ in the year 1990 to 
$21.1 / 10^{5}$ in the year 2015 and from 8.9/10 in the year 1990 to $11.0 / 10^{5}$ in the year 2015, respectively (Fig. 1) [10]. The increase of incidence was predominantly observed in the 15-30-year age group. In women between 30 and 44 years of age the incidence rates remained at a similar level over the period of 26 years of follow-up. Again, the increase of ovarian cancer incidence was noticed among women aged $55+$ years. In 1990, the highest incidence was recorded in the age group 50-54 years $\left(36.6 / 10^{5}\right)$, while in 2015 the highest incidence was recorded in the age range 65-69 years, and it was $50.5 / 10^{5}$ (Fig. 2).

The survival curve was very steep up to five years, at which point it dropped below 0.5. Significant change was observed especially in the first and the second year after

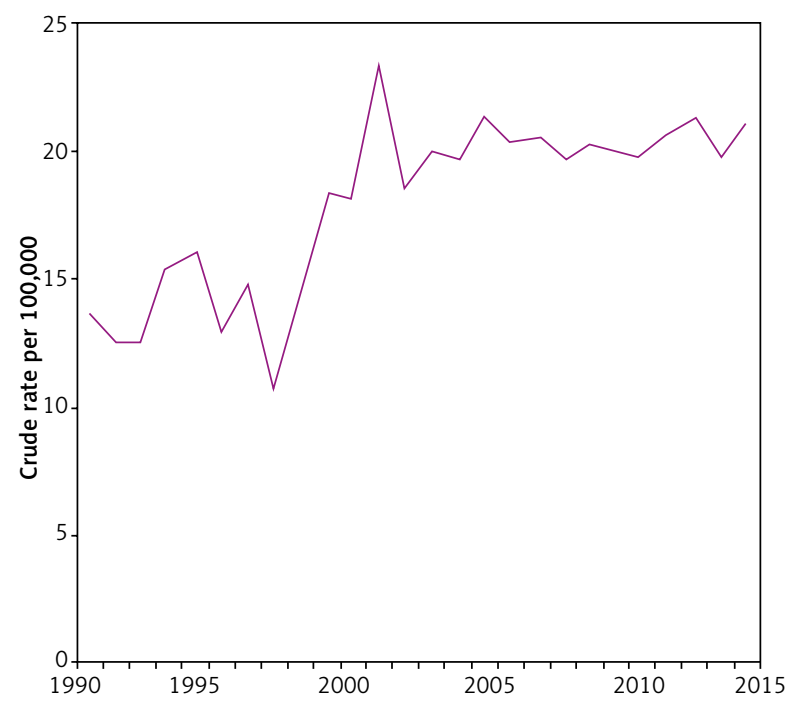

Fig. 1. Ovarian cancer morbidity in women aged 15-99 years in the Podkarpackie province in the years 1990-2015

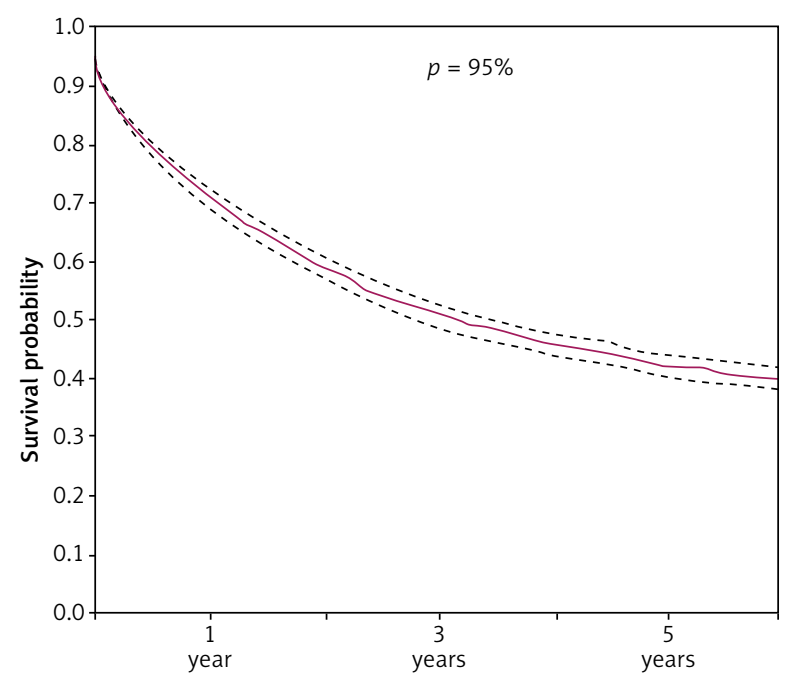

diagnosis when, at the end of the first and the second year, the survival rate dropped to 0.808 and 0.67 , respectively. After 10 years the survival curve becomes flat and the 10-year survival rate is around 0.4 (Fig. 3).

More details can be obtained by plotting the survival curve in relation to some clinical variables. Figure 4 demonstrates the survival rate according to histological type of ovarian cancer.

Based on our data we can state that adenocarcinoma is the most lethal type of ovarian cancer. The survival rate after one year was 0.64, while for the other common types, such as serous carcinoma, mucinous carcinoma, and clear cell carcinoma, it was between 0.82-0.87. After three years the survival rate was about twice as low

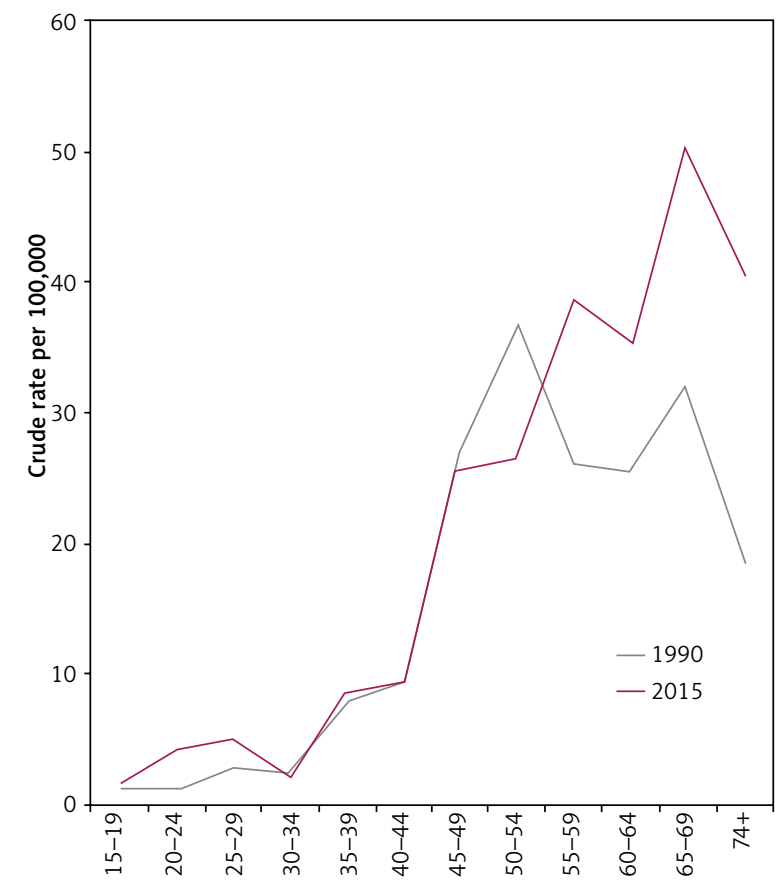

Fig. 2. Ovarian cancer morbidity in women aged 15-99 years in the Podkarpackie province in the years 1990-2015 (age group)

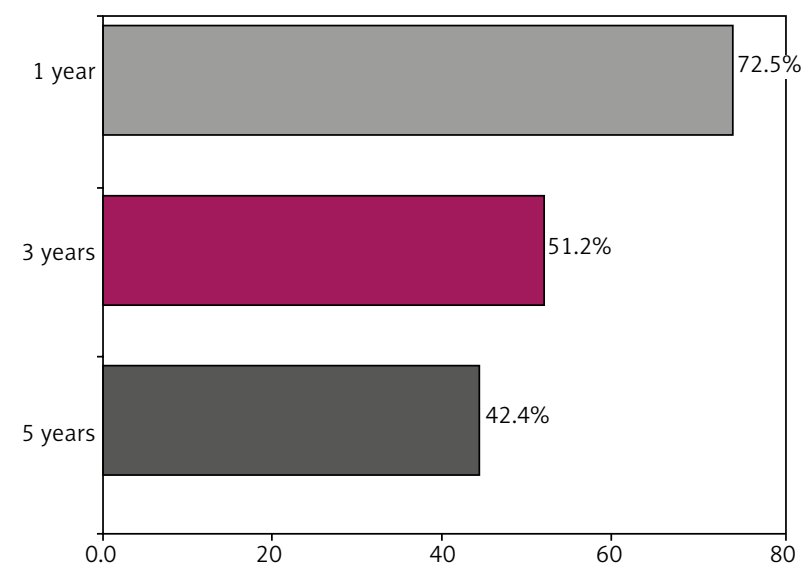

Fig. 3. 1-year, 3-year, and 5-year relative survival rates at ages 15-99 years (patients diagnosed in 1990-2015 in the Podkarpackie province) 
compared to other patients and dropped to 0.27 after five years. The highest short-term survival rates were observed for serous carcinoma and endometrioid carcinoma (0.87), but the long-term survival rates were more promising for mucinous carcinoma (0.61) compared to serous carcinoma (0.47).

The Cox model was run to examine statistical significance of differences between survival rates among different types of cancer. It transpired that all of them have different patterns of survival. Adenocarcinoma had a $23.1 \%$ higher risk of death in the subsequent month than the other common subtypes, while mucinous carcinoma had a $51.5 \%$ lower risk of death than the rest of the subtypes. Model covered 85\% histological types of cancer (Table 1).

Nevertheless, to get the full picture of survival ratios, we need to include other crucial variables to estimate the pure share of certain types of cancer in the evaluation of the hazard ratio. To do so, we added age of the patient, stage of cancer, and area of residence: urban or rural. This model of parameters was estimated on a sample of 2399 cancer incidences consisting of 1138 censored observations and 1261 events. Estimation results are presented below (Table 2).

As expected, age and stage of cancer have a significant impact on the observed hazard ratio. Endometrioid carcinoma, serous carcinoma, and mucinous carcinoma have different paths of survival. Surprisingly, adenocarcinoma has no significant impact on hazard ratio, but patients with adenocarcinoma have worse chances of survival than other patients. Further exploration of data revealed that adenocarcinoma is positively correlated with the stage of cancer, in contrast to other types of cancer. It turns out that $42.5 \%$ of patients with that type of cancer were di-

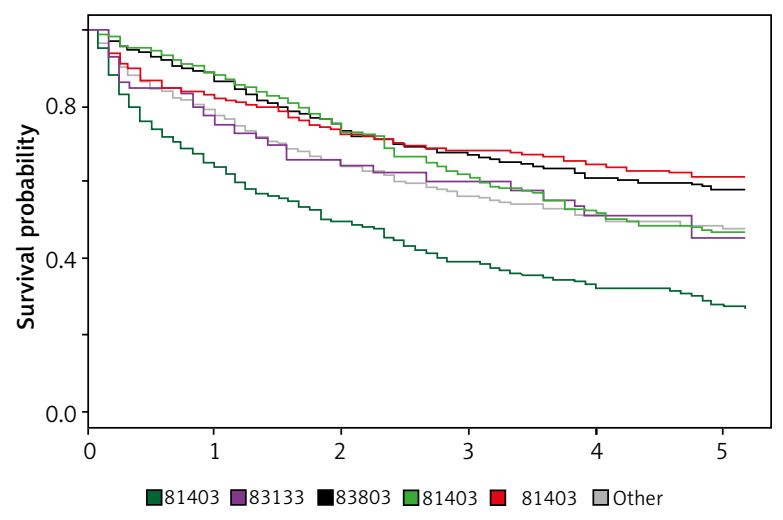

Fig. 4. Survival curve by histological type of cancer

agnosed at a distant stage of cancer, while in other ovarian cancer types distant metastases were only present in around $29 \%$ of patients.

The correlation between the age of the patient at the time of cancer diagnosis and survival was also examined. The analyses showed that with the increase of women's age at the time of diagnosis of the disease, the survival rate decreased. Comparing survival in the $65+$ years age group with, women aged 45-64 years, there was a decrease in one-, three-, and five-year survival by $25.3,24.2$, and $22.9 \%$, respectively. In relation to the age group of 15-44 years, the difference was even greater and amounted 32.9, 39.9, and 42.2\%, respectively (Fig. 5).

In 1990 ovarian cancer in the local stage was diagnosed in $33.3 \%$ of cases. In 2015 the percentage increased to $41.3 \%$. The percentage of diagnoses in the regional and generalised stage within the period of 26 years of observation declined by $6.2 \%$ and $3.1 \%$, respectively. It is worry-

Table 1. Model results

\begin{tabular}{|c|c|c|c|c|c|}
\hline & Percent & Coefficient & Hazard ratio & $p$-value & Significance \\
\hline Adenocarcinoma & 20 & 0.208 & 1.231 & 0.001 & $* * *$ \\
\hline Endometrioid carcinoma & 16 & -0.604 & 0.546 & $<0.001$ & $* * *$ \\
\hline Serous carcinoma & 30 & -0.416 & 0.659 & $<0.001$ & $* * *$ \\
\hline Mucinous carcinoma & 10 & -0.724 & 0.485 & $<0.001$ & $* * *$ \\
\hline Clear cell carcinoma & 3 & -0.437 & 0.646 & 0.018 & ** \\
\hline
\end{tabular}

${ }^{* *} p$-value $0.01-0.05 ;{ }^{* * *} p$-value $<0.01$

Table 2. Model results

\begin{tabular}{|c|c|c|c|c|}
\hline & Coefficient & Hazard ratio & $p$-value & Significance \\
\hline Age & 0.033 & 1.033 & $<0.001$ & $* * *$ \\
\hline Urban area & -0.054 & 0.947 & 0.247 & \\
\hline Stage & 0.618 & 1.856 & $<0.001$ & $* * *$ \\
\hline Adenocarcinoma & 0.045 & 1.046 & 0.495 & \\
\hline Endometrioid carcinoma & -0.420 & 0.657 & $<0.001$ & $* * *$ \\
\hline Serous carcinoma & -0.356 & 0.700 & $<0.001$ & $* * \star$ \\
\hline Mucinous carcinoma & -0.353 & 0.702 & 0.001 & $* \star \star$ \\
\hline Clear cell carcinoma & -0.167 & 0.846 & 0.367 & \\
\hline
\end{tabular}

${ }^{* * *} p$-value $<0.01$ 

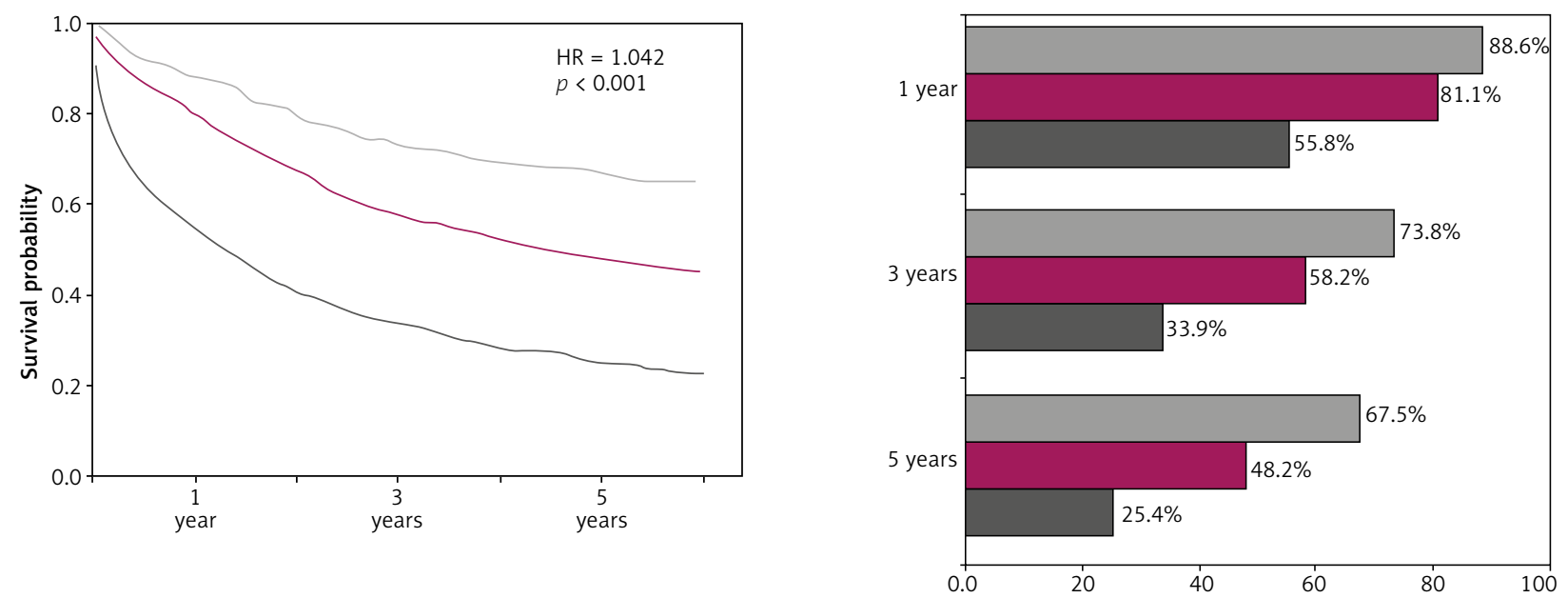

Fig. 5. 1-year, 3-year, and 5-year relative survival rates in women with ovarian cancer diagnosed in the years 1990-2015 in the Podkarpackie province, according to age group
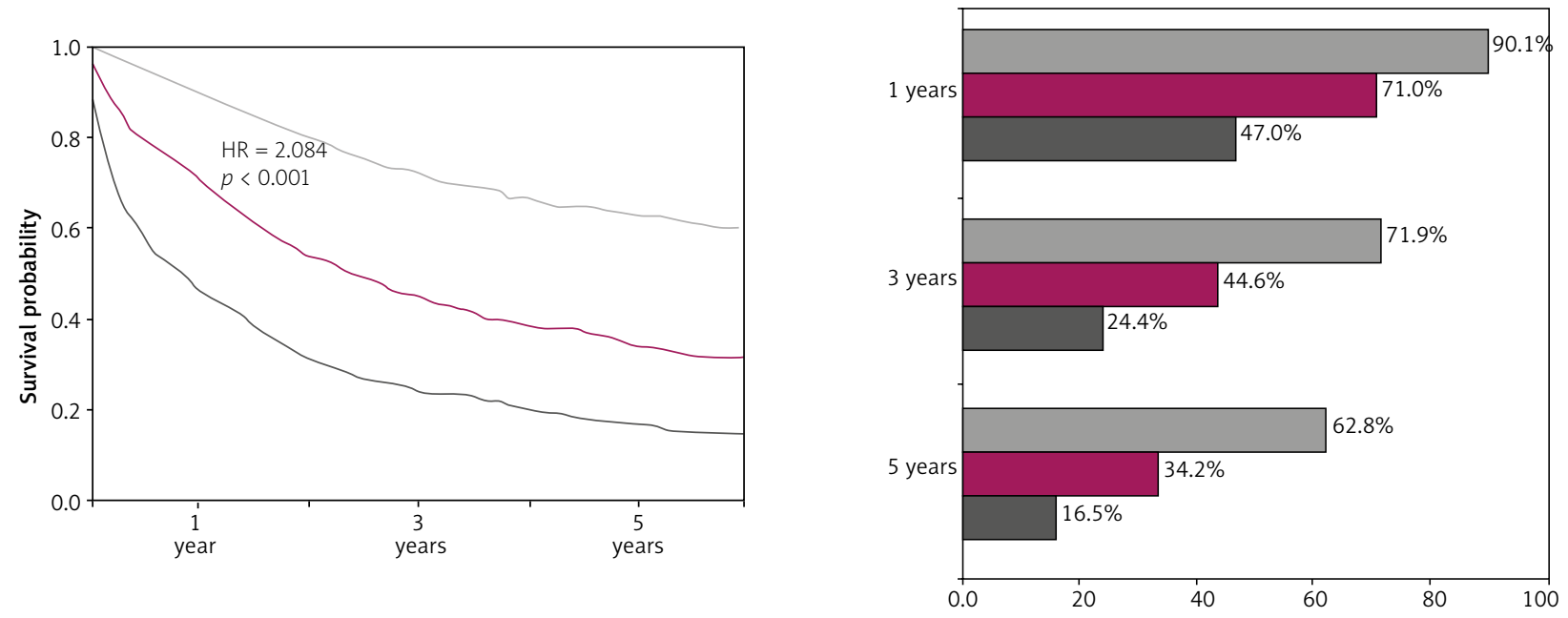

Fig. 6. 1-year, 3-year and 5-year survival rates in women with ovarian cancer in the years 1990-2015, in the Podkarpackie province, according to the stage of the cancer

ing that a significant share of ovarian tumours were diagnosed as unspecified - on average 19.1\% (Table 3).

Significant differences in survival curves were observed. For the generalised stage IV the survival rate fell quickly, and at the end of the first and the second year it was 0.572 and 0.399 , respectively, which is almost equal to the longterm survival rate in the whole sample. After 5 and 10 years, survival rates dropped to 0.211 and 0.1145 , respectively. The regional stage had a slightly bit worse scenario then on average. In comparison to the whole sample, survival rates were lower by $0.037,0.067,0.092$ and 0.099 , respectively, reaching $0.771,0.603,0.408$, and 0.301 after the first, second, fifth, and $10^{\text {th }}$ year of observation, respectively.

It is obviously important to diagnose the cancer as soon as possible looking at the survival curve for the local stage of cancer. The survival rate after the first year was 0.909 and one year later fell to the still high value of 0.822. Even in the long-term we can observe a very high survival rate reaching 0.588 after 10 years of observation. With the ad- vancement of the neoplastic process, the probability of death in the next month increases 2.084-fold (Fig. 6).

The analysis of the relationship between the survival rate of patients with ovarian cancer and their place of residence showed that urban residents had slightly longer one-, three-, and five-year survival, respectively $(75.2 \%, 52.0 \%, 43.8 \%)$ than women living in rural areas (70.2\%, 50.6\%, 41.2\%). Residents of cities have, on average, a 0.906 -fold lower probability of death within the next month, in comparison to the entire population (Fig. 7).

\section{Discussion}

Survival curves are useful for survival analysis but are limited to analysis with respect to one variable at a time. Moreover, they cannot be a discrete variable because there are many possibilities and, consequently, many survival curves. Therefore, to analyse the impact of many variables on survival rate concurrently, we need to use a model. The age of the patient and stage of cancer are obvious choices. With the year as a variable, we can express the state 

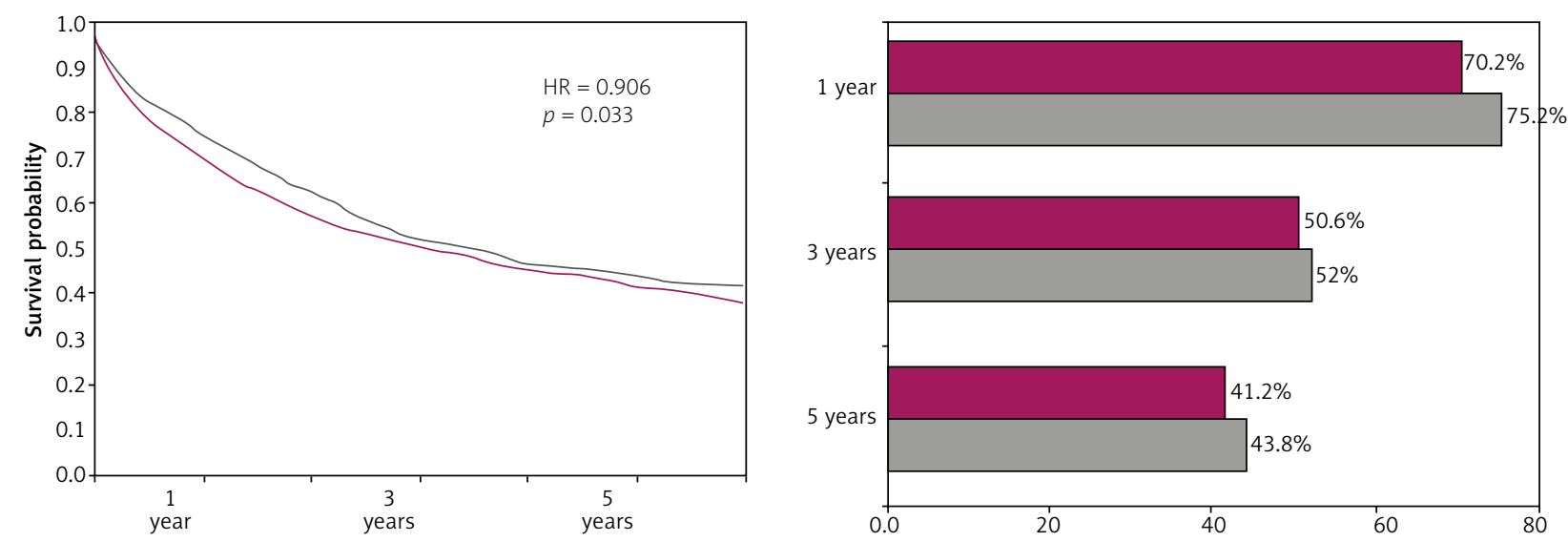

Fig. 7. 1-year, 3-year, and 5-year survival rates in women with ovarian cancer in the years 1990-2015 in the Podkarpackie province, depending on the place of residence.

of available treatment methods and health care trends in general.

Our model shows that all of the primary variables (age, year, stage) as well as different types of tumour have a significant impact on the survival rate of patients with ovarian cancer. With each year of patient age at the moment of cancer diagnosis, the probability of death in the next month is 1.0385 time greater than average. In terms of the hazard ratio, the hazard is greater by $3.85 \%$ comparing to baseline hazard. Each year of health care system change and health care trend change in society decreases the hazard by $1.82 \%$. The most significant result is observed for the stage of cancer. The higher the stage of the cancer, the higher the probability of death in the next month. Results for different types of cancer are also noticeable.

According to common knowledge, age and stage of tumour at the time of diagnosis have a significant impact on the prognosis and further survival of a patient with cancer. It is surprising, however, that despite the low risk factor, women suffering from ovarian adenocarcinoma have lower survival rates than others, and as many as $42.5 \%$ of patients with glandular cancer were diagnosed in stage IV. The above results may suggest that the cancer coding present in the database of the Podkarpackie Cancer Registry (in this case 8140/3 adenocarcinomas) may be secondary tumours,

Table 3. Percentage of individual stages of malignant ovarian cancers diagnosed in Podkarpackie province in the years 1990-2015, in 5 -year periods

\begin{tabular}{lcccc} 
Year & \multicolumn{4}{c}{ Advanced stage } \\
\cline { 2 - 5 } & $\begin{array}{c}\text { Stage I-II } \\
(\%)\end{array}$ & $\begin{array}{c}\text { Stage III } \\
(\%)\end{array}$ & $\begin{array}{c}\text { Stage IV (distant } \\
\text { metastases) (\%) }\end{array}$ & $\begin{array}{c}\text { Undefined } \\
(\%)\end{array}$ \\
\hline 1990 & 33.3 & 21.0 & 28.6 & 17.1 \\
1995 & 47.6 & 19.0 & 20.0 & 13.3 \\
\hline 2000 & 37.0 & 9.1 & 24.0 & 29.9 \\
2005 & 36.5 & 16.9 & 25.9 & 20.6 \\
2010 & 42.9 & 13.6 & 28.3 & 15.2 \\
\hline 2015 & 41.3 & 14.8 & 25.5 & 18.4 \\
Mean & 39.8 & 15.7 & 25.4 & 19.1
\end{tabular}

erroneously diagnosed as primary ovarian cancer. Kubeček et al. indicate that secondary ovarian cancers account for $10-25 \%$ of all ovarian tumours. The most common cancers that cause ovarian metastasis include breast, colon, endometrial, gastric, and appendix cancers, i.e. glandular adenomas. Correct diagnosis is difficult due to the pelvic anatomy [11]. The above is also supported by the fact that patients with this diagnosis were diagnosed when distant metastases had already occurred. Hence, worse response to treatment and shorter survival was observed.

Landen et al. and Kars and Drapkin, in two independent studies, showed that serous carcinomas are characterised by high aggressiveness and quickly metastasize in the pelvic region, whereas endometrioid and mucinous cancers

Table 4. 1-year, 3-year, and 5-year relative survival rates in patients aged 15-99 years diagnosed in Europe between 2000 and 2007 [21]

\begin{tabular}{|c|c|c|c|}
\hline \multirow[t]{2}{*}{ Country } & \multicolumn{3}{|c|}{ Prevalence } \\
\hline & 1-year & 3-year & 5-year \\
\hline Sweden & 82.9 & 58.5 & 46.8 \\
\hline France & 79.3 & 55.5 & 42.5 \\
\hline Finland & 78.8 & 58.8 & 46.5 \\
\hline Slovenia & 78.1 & 52.3 & 43.5 \\
\hline Norway & 77.7 & 54.8 & 43.6 \\
\hline Germany & 75.3 & 52.6 & 42.1 \\
\hline Austria & 73.4 & 53.6 & 43.9 \\
\hline European average & 73.3 & 51.1 & 40.8 \\
\hline Denmark & 73.2 & 48.6 & 37.9 \\
\hline Italy & 72.2 & 50.4 & 40.3 \\
\hline Slovakia & 71.8 & 51.2 & 42.3 \\
\hline Poland & 71.7 & 52.2 & 42.0 \\
\hline Czech Republic & 71.7 & 51.4 & 41.6 \\
\hline Latvia & 70.5 & 47.7 & 39.6 \\
\hline Estonia & 67.2 & 45.7 & 37.7 \\
\hline Lithuania & 65.9 & 45.1 & 36.5 \\
\hline United Kingdom & 63.6 & 40.4 & 31.5 \\
\hline
\end{tabular}


demonstrate lower aggressiveness, usually limited to the ovaries [12, 13].

A strong correlation was also found between tumour histology and the clinical response to chemotherapy. Serous carcinomas initially provide a quick response to treatment, while clear cell carcinomas may show drug resistance due to five-year survival rate (20-30\%) [14-16]. Indicators of one-, three-, and five-year relative survival observed in patients aged 15-99 years in Podkarpackie province in the years 1990-2015 are comparable with the nationwide results received from the National Council [17]. For the country in the analysis carried out among patients aged 15-99 years, diagnosed in 2000-2002, one-, three-, and five-year survival rates were $71.9 \%, 50.5 \%$, and $42.0 \%$, respectively [8]. For comparison, the ratios for the Podkarpackie region were $72.5 \%, 51.2 \%$, and $42.4 \%$, respectively. The National Cancer Registry noted a slight (0.6 pp) increase in the five-year relative survival rate of patients treated for ovarian cancer, examined in two periods: 2000-2002 (42.0\%) and 20032005 (42.6\%). The highest value of the indicator was recorded in the Zachodniopomorskie voivodship (49.8\%) and the lowest in the Lubuskie voivodeship (36.7\%) [18].

The results of a study conducted by the European Cancer Registry (EUROCARE) indicate an improvement in fiveyear survival of patients with ovarian cancer in Poland. In the EUROCARE 4 study [19] covering 1995-1999 five-year survival was $38.9 \%$, which is, in relation to the EUROCARE 5 study [20], an increase of $3.1 \%$.

According to the report presented in the Green Book, prepared by the National Health Fund (NFZ), expenditures incurred in the first year for treatment of patients with ovarian cancer increased in Poland by almost $60 \%$ from 2005 to 2012. In 2014, only 117 patients with ovarian cancer participated in drug programs dedicated to patients with cancer; the largest group in the Śląskie voivodeship (46 people), and the lowest in the Podkarpackie and Opolskie voivodships [17].

In the Podkarpackie province, this situation has significantly improved. In the Podkarpackie Oncology Centre in Rzeszów in 2017, 50 women with advanced ovarian cancer (as of 08/11/2015, data from the AMMS system, Clinical Provincial Hospital No. 1 in Rzeszów) were qualified for the dedicated drug program.

In Europe. the highest five-year survival rates were recorded in Sweden, Finland, and Austria (46.8\%, 46.5\%, and $43.9 \%$, respectively), while the lowest were in the United Kingdom, Lithuania, and Estonia (31.5\%, 36.5\%, and 37.7\%, respectively). The five-year survival among elderly women treated for ovarian cancer in Poland oscillates around the level of average values for other European countries, deviating from the countries in which the highest survival rate is recorded by a maximum of $4.8 \%$ (Table 4) [21].

Analysing the influence of patient's age, at the time of diagnosis, on the length of survival, taking into account the relative risk $(H R)$, it was shown that with each subsequent year of life, the probability of death in the next month increases by 1.042 times, and the calculated variables are statistically significant. It should be noted, however, that in women over 65 years of age, it will undoubtedly be affected by age-associated diseases as well as postmenopausal hormone management. However, in this age range, according to the prognosis published by the National Council of Emergency, the incidence of ovarian cancer will increase by about $1 \%$ per year. In the remaining age groups, a decrease in the number of cases is expected in the group of 20-44-year-olds by $2.0 \%$, and in the group of $45-64$ years by $1.2 \%$, annually [3].

The increase in the total number of ovarian cancer cases, especially among women aged 65+ years, will be related to changes in the population structure (its aging), according to data presented by the Central Statistical Office. In 2050 the population of Poland will amount to 33,951,000, which compared to 2013 means a decrease in the population by 4.55 million, i.e. by $12 \%$. People aged $65+$ will account for almost $1 / 3$ of the population, and their number will increase by 5.4 million compared to 2013. In turn, women of childbearing age in 2050 will account for only $62 \%$ of the female population. The expected average life expectancy in women will increase from 81.5 years in 2015 to 88.4 years in 2050 [22]. We will observe a similar situation in Podkarpackie province. The above factors will be reflected in all oncological indicators [17].

An important factor determining the life expectancy of patients with ovarian cancer is their place of residence. One, two-, and five-year experiences in women living in urban areas are, respectively, 5\%, 4.4\%, and $2.6 \%$ higher than for rural women. This may be related to better access to specialists and medical equipment, as well as greater oncology alertness in cities in Podkarpackie. The five-year survival rate estimated for the whole of Poland was $42.0 \%$. The lowest rates were recorded in Lubuskie (36.7\%) and Opolskie $(37.9 \%)$ voivodships and the highest in West Pomeranian (49.8\%) and Świętokrzyskie (46.1\%) voivodships. The difference between the lowest and the highest indicator was 13\%. [18]. According to Black and Welch, regional differences in survival can be influenced by the severity of the disease at the time of diagnosis, the organisation of the oncological care system, the waiting time for treatment, and the quality of diagnostic methods. The authors also pay special attention to the huge role of effective screening programs, the existence of which in a substantial way translates into early diagnosis, and thus results in prolonging the patient's survival [23]. However, at the present time, there is not a sensitive enough method of ovarian cancer screening. The most important risk factors for ovarian cancer include: carriage of BRCA1 and BRCA2 gene mutations (approximately 13\% of all ovarian cancer cases), hereditary breast and ovarian cancer syndrome, Lynch syndrome, as well as childlessness and ineffective ovulation stimulation [24].

The most important factor determining the survival time of patients with ovarian cancer is the stage of the disease at the time of diagnosis.

When comparing the length of the experience with respect to the stage of development, it was found that in patients who were diagnosed with a disease in the generalised stage, one-, three-, and five-year survival were lower by $43.1 \%, 47.5 \%$, and $46.3 \%$ than women diagnosed at the stage of local sophistication. According to the NCR data, the diagnosis in the early stage of the disease concerns only $20-30 \%$ of patients, with five-year survival in this group of 
patients at the level of $90 \%$. In the third and fourth tumour stage, almost $70 \%$ of ovarian cancer cases were diagnosed. Remarkably, five-year survival in this group was only $25 \%[17]$.

According to a study conducted by Jemal et al., only 30\% of patients in the advanced stage of the disease survive five years from the diagnosis [25]. In turn, Jelovac et al. showed that, despite the huge progress made in medicine, the fiveyear survival rate in patients with ovarian cancer from 1975 to 2011 increased by only $8 \%$, and ovarian cancer remains a "silent female killer" [26].

\section{Conclusions}

Despite the huge progress that has been made in medicine, survival of patients with ovarian cancer still remains at a similar level as it did 20 years ago.

Survival of women with ovarian cancer in Podkarpackie province is comparable with the rates calculated for the whole of Poland, and the results obtained are statistically significant.

Survival in women living in cities is higher than among rural women. Significant efforts should be taken to increase oncological alertness both in the medical community and among the inhabitants of villages in Podkarpacie.

Despite the low risk factor, women suffering from ovarian adenocarcinoma, have lower survival rates than others, and as many as $42.5 \%$ of patients with adenocarcinoma were diagnosed in stage IV. Steps aiming to improve the detectability of ovarian tumours in the earliest possible stage should be taken. This should increase the survival rates in each age group.

The authors declare no conflict of interest.

\section{References}

1. Didkowska J, Wojciechowska U. Epidemiology of genital malignancies in the females in Poland. Curr Gynecol Oncol 2012; 10: 25-37.

2. Wojciechowska U, Didkowska J. Illnesses and deaths from malignant tumors in Poland. National Cancer Registry. Maria Sklodowska-Curie Institute - Oncology Center. Available at: http://onkologia.org.pl/ raporty/ (access: 11.11.2017).

3. Didkowska J, Wojciechowska U, Zatoński W. Prediction of cancer incidence and mortality in Poland up to the year 2025. Warszawa 2009.

4. McLemore MR, Miaskowski C, Aouizerat BE, Chen L-M, Dodd MJ. Epidemiologic and Genetic Factors Associated with Ovarian Cancer. Cancer Nurs 2009; 32: 281-290.

5. Szatkowski W, Muzykiewicz K, Jasiówka M, Karolewski K, Kojs Z, Klimek M, Blecharz P. Comparison of effectiveness of treatment of patients with sporadic and germline BRCA1-related ovarian cancer. Ginekol Pol 2016; 87: 422-425.

6. Synowiec A, Wcisto G, Bodnar L, Gasowska-Bodnar A, Szczylik C. Screening for ovarian cancer in BRCA1/BRCA2 mutations carriers. Ginekol Pol 2014; 85: 377-381.

7. Markowska J, Kornafel J, Karolewski K, et al. Recommendations of Polish Gynecological Oncology Society concerning epithelial tumors of the ovary: ovarian cancer and borderline tumors. Curr Gynecol Oncol 2013; 11: 9-23.

8. Wojciechowska U, Didkowska J, Zatoński W. Survival of cancer patients diagnosed in 2000-2002 in Poland. Warsaw 2009.

9. Hakulinen T. Cancer survival corrected for heterogeneity in patient withdrawal. Biometrics 1982; 38: 933-942.
10. Grądalska-Lampart M, Radziszewska A, Patro A. Cancer in Podkarpackie voivodship in 2015. Rzeszow 2017.

11. Kubeček O, Laco J, Špaček J, Petera J, Kopecký J, Kubečková A, Filip S. The pathogenesis, diagnosis, and management of metastatic tumors to the ovary: a comprehensive review. Clin Exp Metastasis 2017; 34: 295-307.

12. Landen CN, Birrer MJ, Sood AK. Early events in the pathogenesis of epithelial ovarian cancer. J Clin Oncol 2008; 26: 995-1005.

13. Kars AM, Drapkin R. Ovarian cancer pathogenesis: a model in evolution. J Oncol 2010; 2010: 932371.

14. Itamochi H, Kigawa J, Sugiyama T, Kikuchi Y, Suzuki M, Terakawa N. Low proliferation activity may be associated with chemoresistance in clear cell carcinoma of the ovary. J Obstet Gynecol 2002; 100: 281-287.

15. Sugiyama T, Kamura T, Kigawa J, et al. Clinical characteristics of clear cell carcinoma of the ovary: a distinct histologic type with poor prognosis and resistance to platinum-based chemotherapy. Cancer 2000; 88: 2584-2589.

16. Herzog TJ, Pothuri B. Ovarian cancer: a focus on management of recurrent disease. Nat Clin Pract Oncol 2006; 3: 604-611.

17. Kozierkiewicz A, Topór-Mądry R (eds.). Zielona Księga. Rak jajnika: zapobieganie, rozpoznawanie, leczenie. Polskie Towarzystwo Onkologiczne, Warszawa 2015.

18. Wojciechowska U, Didkowska J, Zatoński W. Cancer in Poland - fiveyear survival rates by regions. Warszawa 2010.

19. Berrino F, De Angelis R, Sant M, Rosso S, Bielska-Lasota M, Coebergh JW, Santaquilani M; EUROCARE Working group. Survival for eight major cancers and all cancers combined for European adults diagnosed in 1995-99: results of the EUROCARE-4 study. Lancet Oncol 2007; 8: 773-783.

20. Sant M, Chirlaque Lopez MD, Agresti R, et al. Survival of women with cancers of breast and genital organs in Europe 1999-2007: Results of the EUROCARE-5 study. Eur J Cancer 2015; 51: 2191-2205.

21. https://w3.iss.it/site/EU5Results/forms/SA0007.aspx (access: 11.11.2017).

22. Population forecast for 2014-2050. Chief Statistical Office. Department of Demographic and Labor Market Research, Warszawa 2014.

23. Black WC, Welch HG. Advances in diagnostic imaging and overestimations of disease prevalence and the benefits of therapy. N Engl J Med 1993; 328: 1237-1243.

24. Markowska J, Kornafel J, Karolewski K, et al. Recommendations of the Polish Society of Oncological Gynecology on epithelial ovarian tumors: ovarian cancer and borderline malignancy. Curr Gynecol Oncol 2013; 11: 9-23.

25. Jemal A, Siegel R, Ward E, Hao Y, Xu J, Murray T, Thun MJ. Cancer statistics. Cancer J Clin 2008; 58: 71-96.

26. Jelovac D, Armstrong DK. Recent Progress in the Diagnosis and Treatment of Ovarian Cancer. Cancer J Clin 2011; 61: 183-203.

\section{Address for correspondence}

\section{Aneta U. Radziszewska}

Department of Epidemiology and Podkarpackie Cancer Registry Podkarpackie Oncology Centre

2 Szopena St.

35-055 Rzeszow, Poland

e-mail: radziszewska.aneta@interia.pl

Submitted: 5.03 .2018

Accepted: $\quad 10.05 .2018$ 